\title{
Prepulse Inhibition and Habituation of Acoustic Startle Response in Male MDMA ('Ecstasy') Users, Cannabis Users, and Healthy Controls
}

\author{
Boris B Quednow*,', Kai-Uwe Kühn', Klaus Hoenig', Wolfgang Maier' and Michael Wagner' \\ 'Department of Psychiatry, University of Bonn, Germany
}

\begin{abstract}
Chronic administration of 3,4-methylenedioxymethamphetamine (MDMA) is associated with long-term depletion of serotonin (5-HT) and loss of $5-\mathrm{HT}$ axons in the brains of rodents and nonhuman primates. Despite the broad database concerning the selective serotonergic neurotoxicity of recreational MDMA consumption by humans, controversy still exists with respect to the question of whether the well-known functional consequences of these neurotoxic effects, such as memory impairment, were caused by chronic 5-HT deficiency. Habituation and prepulse inhibition (PPI) of the acoustic startle response (ASR) can be used as a marker of central serotonergic functioning in rodents and humans. Thus, we investigated the functional status of the central serotonergic system in chronic but abstinent MDMA users by measuring PPI and habituation of ASR. PPI and habituation of ASR were measured in three groups. The first group (MDMA group) included 20 male drug-free chronic users of MDMA; the second group (cannabis group) consisted of 20 male drug-free chronic users of cannabis; and the third group (healthy controls) comprised 20 male participants with no history of illicit drug use. Analysis revealed significantly increased PPI of MDMA users compared to those of cannabis users and healthy controls. Cannabis users and healthy controls showed comparable patterns of PPI. There were no differences in habituation among the three groups. These results suggest that the functional consequences of chronic MDMA use may be explained by 5-HT receptor changes rather than by a chronic 5-HT deficiency condition. Use of cannabis does not lead to alterations of amplitude, habituation, or PPI of ASR.

Neuropsychopharmacology (2004) 29, 982-990, advance online publication, 18 February 2004; doi: I 0. I038/sj.npp. I 300396
\end{abstract}

Keywords: MDMA; cannabis; sensorimotor gating; habituation; acoustic startle response; prepulse inhibition

\section{INTRODUCTION}

The startle reflex is a fast response to a sudden, intense stimulus such as a loud sound and consists of contraction of the skeletal and facial musculature. This reflex is usually classified as a defensive response. The acoustic startle response (ASR) of mammals is mediated by a simple threesynapse neuronal circuit located in the lower brainstem. Neurons of the caudal pontine reticular nucleus are key elements of this primary ASR pathway (Davis et al, 1982; Koch, 1999). In humans, the eye-blink component of the ASR is quantified by using electromyographic (EMG) measurements of the orbicularis oculi facial muscle (Hoffman and Searle, 1968). The startle reflex shows several forms of behavioral plasticity, such as prepulse inhibition (PPI) and habituation. PPI refers to the reduction of ASR

*Correspondence: BB Quednow, Department of Psychiatry, University of Bonn, Sigmund-Freud-Straße 25, D-53105 Bonn, Germany,

Tel: + 49228287568 I, Fax: + 492282876949 ,

E-mail: boris.quednow@ukb.uni-bonn.de

Received 19 May 2003; revised 09 December 2003; accepted 21 December 2003

Published online 05 January 2004 at http://www.acnp.org/citations/ Npp I050403226/default.pdf magnitude when a distinctive nonstartling stimulus is presented $30-500 \mathrm{~ms}$ before the startling stimulus. PPI is used as an operational measure for sensorimotor gating that reflects the ability of an organism to properly inhibit sensory information (Graham, 1975; Hoffman and Ison, 1980). Habituation is a theoretical construct that refers to the reduction in magnitude of ASR after repeated presentation of the startling stimulus that is not due to muscle fatigue or blunting of sensory receptor responsiveness (Groves and Thompson, 1970).

The magnitude, habituation, and PPI of the ASR are neurobiological measures that are consistent phenomena across species and are widely used to investigate sensorimotor gating and information processing (Braff et al, 1992; Geyer and Braff, 1987; Swerdlow et al, 1999).

3,4-Methylenedioxymethamphetamine (MDMA, 'ecstasy') is a drug that is widely abused, especially by young people (Christophersen, 2000). In animals, administration of MDMA produces a rapid and marked release of serotonin (5-HT) via inhibition and reversal of the 5-HT transporter (Rudnick and Wall, 1992). There is convincing evidence that MDMA produces a substantial and sustained long-term neurotoxic loss of 5-HT nerve terminals with an associated depletion of 5-HT in several brain regions of rats, guinea 
pigs, and several species of nonhuman primates (Stone et al, 1986; Commins et al, 1987; Schmidt, 1987; Battaglia et al, 1988; Insel et al, 1989; Wilson et al, 1989; Ali et al, 1993; Scheffel et al, 1998; Hatzidimitriou et al, 1999; Taffe et al, 2001). Studies of MDMA use in humans have also shown selective decrements in cerebrospinal fluid (CSF) concentrations of 5-hydroxy indoleacetic acid (5-HIAA) as a marker for central serotonergic depletion, with no alterations in CSF homovanillic acid (HVA) or 3-methoxy-4hydroxyphenylglycol (MHPG), the major metabolites of dopamine and norepinephrine, respectively (McCann et al, 1994, 1999). Finally, an already huge body of evidence is growing concerning neurotoxic effects and associated neuropsychiatric consequences of recreational MDMA consumption in humans, such as impaired cognition, altered behavior, and increased risk of psychiatric illness (for reviews, see McCann et al, 2000; Morgan, 2000; Parrott, 2000, 2001; Gouzoulis-Mayfrank et al, 2002b; Montoya et al, 2002). However, it remains unclear if these functional consequences following chronic MDMA ingestion are an effect of a chronic 5-HT deficiency condition (Kish, 2002).

One approach to measure the functional status of the serotonergic system in chronic users of MDMA might be offered by measurement of ASR, because several conditions of ASR are sensitive to psychotropic drugs and were used as functional markers of neurotransmitter systems in animals and humans in previous studies (Braff et al, 2001; Geyer et al, 2001).

Work with rodents suggests that acute administration of 5 -HT releasers like MDMA, $\alpha$-ethyltryptamine (AET), and MDEA disrupts PPI (Mansbach et al, 1989; Kehne et al, 1996; Martinez and Geyer, 1997; Vollenweider et al, 1999) and reduces habituation of ASR (Martinez and Geyer, 1997). In contrast, acute MDMA administration in humans increased PPI and did not alter habituation of ASR (Vollenweider et al, 1999; Liechti et al, 2001). MDMA and AET had no effect on the general startle reactivity (mean amplitude of ASR) in humans and rodents (Martinez and Geyer, 1997; Vollenweider et al, 1999; Liechti et al, 2001).

Acute administration of the 5-HT-depleting agent p-chlorophenylalanine (PCPA) disrupted PPI in rodents (Fletcher et al, 2001; Prinssen et al, 2002). This finding is consistent with results of a previous study, which reported decreased PPI after dietary tryptophan depletion in humans (Phillips et al, 2000). The reported effects of 5-HT-depleting agents on habituation in rodents are contradictory: in rats, depletion of 5-HT by PCPA or p-chloroamphetamine slowed down habituation of ASR (Conner et al, 1970; Carlton and Advokat, 1973). However, other studies failed to replicate this effect (Davis and Sheard, 1976; Overstreet, 1977), and one study reported acceleration of tactile startle habituation (Geyer and Tapson, 1988). 5-HT or tryptophan depletion and habituation of ASR in humans have not yet been investigated. Depletion of 5-HT increased the baseline startle amplitude in rats (Conner et al, 1970; Carlton and Advokat, 1973), but not in humans (Phillips et al, 2000). It is noteworthy that the effects of serotonergic drugs on PPI and habituation of ASR reported above were studied only for acute administration. Chronic administration of MDMA and other serotonergic substances and their effects on several conditions of ASR have not yet been studied in humans.
In addition, some investigations have reported PPI deficits in neuropsychiatric disorders with a supposed serotonergic component such as obsessive-compulsive disorder (Swerdlow et al, 1993) and Tourette's syndrome (Castellanos et al, 1996; Swerdlow et al, 2001).

The aim of the present study was to investigate the functional status of the serotonergic system in users of MDMA by ASR measurement. Thus, we measured magnitude, habituation, and PPI in chronic but recently abstinent MDMA users compared to those attributes of a clinical control group of cannabis users and healthy controls with no history of drug abuse. The comparison with a control group of cannabis users allowed us to estimate the influence of the common concomitant use of cannabis in MDMA users, which is discussed in previous works as being a strong biasing factor in research with MDMA consumers (Croft et al, 2001; Daumann et al, 2001; Gouzoulis-Mayfrank et al, 2002a).

\section{MATERIALS AND METHODS}

\section{Participants}

PPI and habituation of ASR were measured in three groups. The first group (MDMA group) included 20 male drug-free chronic users of MDMA; the second group (cannabis group) consisted of 20 male drug-free chronic users of cannabis; and the third group (healthy controls) comprised 20 male participants with no history of illicit drug use. MDMA users were recruited by advertisement in a techno music magazine. Cannabis users and healthy controls were recruited by advertisement in a local newspaper. Subjects of the MDMA group were required to have used MDMA at least 50 times over a period of at least 1 year. In addition, the use of MDMA had to clearly outweigh the consumption of any other psychotropic drug. To be eligible for inclusion in the cannabis group, no significant previous use of amphetamine derivatives like MDMA and no previous use of cocaine was allowed. ASR assessment was carried out when probands were drug free for at least 3 days (period of abstinence, $15.29 \pm 2.64$ days (mean \pm standard error of the mean (SEM))). Inclusion criteria for the healthy controls included negative urine drug test results. Legitimate use of psychotropic medication and/or a history of psychiatric illness were exclusion criteria for all groups. The groups did not differ with respect to age, length of education, and smoking habits. Compared to healthy controls, neither the MDMA nor the cannabis group differed concerning intellectual functioning as measured by the MehrfachwahlWortschatz-Intelligenztest (MWT-B) (Lehrl, 1999). However, the MDMA group and the cannabis group differed significantly with respect to verbal intellectual performance. None of the included subjects reported personal or family history of any DSM IV axis I psychiatric diagnosis. None of the participants had a history of migraine, epilepsy, or craniocerebral trauma. The demographic data of the groups are shown in Table 1.

The study was approved by the Ethics Committee of the Medical Faculty of the University of Bonn. After being informed of the aim of the study by written and oral description, all participants gave written informed-consent statements. 
Table I Demographic Data (Means and Standard Errors of the Means)

\begin{tabular}{|c|c|c|c|c|c|c|}
\hline & Total $(n=50, m)$ & $\operatorname{MDMA}(n=17, m)$ & Cannabis $(n=16, m)$ & Controls $(n=17, m)$ & Value $^{a}$ & $p^{a}$ \\
\hline Age & $24.38(5.05)$ & $23.88(5.77)$ & $25.25(4.55)$ & $24.06(4.94)$ & $F=0.34$ & 0.71 \\
\hline Smoker/nonsmoker & $32 / 18$ & $13 / 4$ & $9 / 7$ & $10 / 7$ & $\chi^{2}=1.76$ & 0.41 \\
\hline Verbal IQ $\mathrm{Q}^{\mathrm{b}}$ & $|04.7|(|0.2|)$ & $99.82(|0.6|)$ & | I 0.00 (9.83) & I04.94 (8.00) & $F=4.55$ & 0.02 \\
\hline Years of education & $12.70(1.41)$ & $12.24(1.79)$ & $13.13(0.50)$ & $12.80(1.55)$ & $F=1.74$ & 0.19 \\
\hline
\end{tabular}

aNOVA (over all groups) or $\chi^{2}$ test (over all groups) for frequency data.

$b_{t-T e s t}$ (cannabis vs MDMA), $p<0.01$.

\section{Procedure}

ASR assessments were carried out after informed consent was given by all participants and after the administration of a neuropsychological test battery (the results of the cognitive testing will be published elsewhere). For the estimation of verbal intellectual performance, the Mehrfachwahl-Wortschatz-Intelligenztest (MWT-B) (Lehrl, 1999) was used. In addition, an SKID-I interview conducted according to DSM IV procedures was carried out by a psychologist trained for the use of this instrument. Drug history and present pattern of psychotropic drug consumption were assessed by a structured interview. Subjects who were screened for inclusion in the healthy control group were urine tested for use of drugs. During the psychiatric and neuropsychological assessment, the subjects could ask for a break at any time. Smoking was not prohibited before assessment or during the breaks.

\section{Interview For Psychotropic Drug Consumption}

For the assessment of the use of legal and illegal psychotropic substances, a structured interview was developed that comprised questions concerning quantity, duration, and frequency of present and past consumption of all known psychotropic substances. Quantity of drug consumption was assessed for MDMA in terms of numbers of tablets consumed. For cannabis and other substances, the quantity was measured in terms of times of use, because it was hard to evaluate and define the concept of a single dose. On the basis of the actual and former substance intake, we estimated a cumulative drug dose. It is to be emphasized that this rough estimation is only of heuristic value. The data for pattern and amount of drug consumption of the groups are shown in Table 2.

\section{Startle Response Measurement}

Electrodes were attached while the participants were seated in a comfortable chair. Subjects were advised that they would hear white noise and bursts over the headphones and were instructed to keep their eyes open. The eye-blink component of the ASR was measured by using an electromyographic startle system (EMG-SR-LAB; San Diego Instruments, Inc., San Diego, CA); registration parameters were described in detail elsewhere (Braff et al, 1992). Two silver/silver chloride electrodes were positioned below and to the outer canthus of the right eye over the orbicularis oculi muscle, and a ground electrode was placed on the glabella. All electrode resistances were less than $10 \mathrm{k} \Omega$. Acoustic startle stimuli were presented binaurally through headphones (TDH-39-P; Maico). Each session began with a 4-min acclimation period of 70-dB background white noise that was continued throughout the session. Subjects received 61 sound pulses with a power of $116 \mathrm{~dB}$ and a duration of $40 \mathrm{~ms}$, separated by variable intervals (mean, $15 \mathrm{~s}$ ). In 48 of the trials, the pulse was preceded by a $40-\mathrm{ms}$ prepulse with an interstimulus interval (ISI) of $120 \mathrm{~ms}$ of four levels of intensity $(72,74,78$, and $86 \mathrm{~dB} ; 12$ trials each). All trials were presented in pseudorandomized order. The entire test session lasted about $20 \mathrm{~min}$.

A total of 10 subjects were excluded because of minimal or no startle response (ASR magnitude was $<25 \mathrm{U}$ ) according to the criteria of Braff et al (1992).

\section{Statistical Analysis}

The percent PPI was calculated for each prepulse (PP) trial condition in startle magnitude in the presence of a PP compared to the magnitude of the response to pulse-alone (PA) trials $(\% \mathrm{PPI}=100 \times(\mathrm{PA}-\mathrm{PP}) / \mathrm{PA})$; these data were analyzed by analysis of variance (ANOVA) (group $\times$ prepulse trial condition, with repeated measures at factor intensity) and by $t$-tests for independent samples (within groups). PA trials were pooled in six blocks for assessing habituation; these data were analyzed by ANOVA (block $\times$ group, with repeated measures at factor block). The percent habituation was calculated as the reduction in startle magnitude between the first and last block of PA trials $(\% \mathrm{HAB}=100 \times($ first block-last block $) /$ first block $)$ and the first and the second block; these data were analyzed by ANOVA (group and block $\times$ group, with repeated measures at factor block) and $t$-tests for independent and paired samples (within group). Startle magnitude was assessed for each block of a session by using the mean values of all PA trials; these data were analyzed by ANOVA (group) and by $t$-tests for independent samples. Demographic data were analyzed by ANOVA and by independent t-tests.

The confirmatory statistical comparisons of all data were carried out at a significance level set at $p=0.05$ (two tailed).

\section{RESULTS}

\section{PPI}

Figure 1 shows the percent PPI of ASR in all PP trial conditions. PPI was strongly increased in MDMA users 
Table 2 Pattern and Amount of Illegal Drug use: Results of the Psychotropic Drug Interview (Means and Standard Error of Means) ${ }^{\mathrm{a}}$

\begin{tabular}{|c|c|c|c|}
\hline Drug and Characteristic & MDMA $(n=17, m)$ & Cannabis $(n=16, m)$ & Controls $(n=17, m)$ \\
\hline \multicolumn{4}{|l|}{$\overline{M D M A}$} \\
\hline Tablets per week & ।.7। (2.77) & $0.01(0.05)$ & $0.00(0.00)$ \\
\hline Years of use & $3.71(1.97)$ & $0.13(0.50)$ & $0.00(0.00)$ \\
\hline Cumulative dose (tablets) & $424.64(421.45)$ & $7.93(26.14)$ & $0.00(0.00)$ \\
\hline Last consumption (days) & $15.29(10.88) ; n=17$ & $750.00(975.81) ; n=2$ & $0.00(0.00)$ \\
\hline \multicolumn{4}{|l|}{ Cannabis } \\
\hline Times per week & $1.70(1.64)$ & $4.19(4.91)$ & $0.00(0.00)$ \\
\hline Years of use & $3.47(2.85)$ & $6.60(3.98)$ & $0.00(0.00)$ \\
\hline Cumulative dose (times) & $604.7 \mid(518.60)$ & |074.7| (|4|8.79) & $0.00(0.00)$ \\
\hline Last consumption (days) & $5.53(4.96) ; n=15$ & $6.56(4.88) ; n=16$ & $0.00(0.00)$ \\
\hline Cumulative dose (times) & $222.78(291.75)$ & $17.22(64.85)$ & $0.00(0.00)$ \\
\hline Last consumption (days) & $20.04(41.42) ; n=12$ & $240.00(|69.7|) ; n=2$ & $0.00(0.00)$ \\
\hline \multicolumn{4}{|l|}{ Cocaine } \\
\hline Times per week & $0.04(0.11)$ & $0.02(0.06)$ & $0.00(0.00)$ \\
\hline Years of use & $0.62(1.76)$ & $0.31(0.87)$ & $0.00(0.00)$ \\
\hline Cumulative dose (times) & $4.53(12.93)$ & $2.95(9.83)$ & $0.00(0.00)$ \\
\hline Last consumption (days) & $36.00(20.78) ; n=3$ & $17.50(4.65) ; n=2$ & $0.00(0.00)$ \\
\hline \multicolumn{4}{|l|}{ Hallucinogens } \\
\hline
\end{tabular}

${ }^{a}$ Consumption per week, duration of use, and cumulative dose are averaged within the total group. Last consumption is averaged only for persons who used the drug. In this case, sample size, $n$, is shown.

compared to that in the control groups. An ANOVA (PP intensity $\times$ group, with repeated measures at factor $\mathrm{PP}$ intensity and smoking as a covariable) revealed a significant difference between subject effect $(\mathrm{F}(2.47)=3.30 ; p<0.05)$ and a main effect of the factor PP intensity $(\mathrm{F}(3.141)=87.82 ; p<0.001)]$, reflecting the correlation of PP intensity and PPI. The interaction of intensity and group was not significant $(\mathrm{F}(6.141)=0.93 ; p=0.47)$. An analysis of the within-subject contrasts showed the inverse linear connection of the PP intensity and startle response $(\mathrm{F}(1.47)=161.99 ; p<0.001)$.

ANOVA between the MDMA and the control groups, respectively ( $\mathrm{PP}$ intensity $\times$ group, with repeated measures at factor PP intensity and smoking as a covariable), are also shown to be significant between subject effects $\left(\mathrm{F}_{\text {controls }}(1.32)=4.16 ; \quad p<0.05 ; \quad \mathrm{F}_{\text {cannabis }}(1.31)=5.90\right.$; $p<0.05)$, a significant main effect of the factor intensity $\left(\mathrm{F}_{\text {controls }}(3.96)=65.95 ; \quad p<0.001 ; \quad \mathrm{F}_{\text {cannabis }}(3.93)=66.4\right.$; $p<0.001)$, but no significant interaction was found between intensity and group $\left(\mathrm{F}_{\text {controls }}(3.96)=1.74 ; p=0.17\right.$; $\left.\mathrm{F}_{\text {cannabis }}(3.93)=0.22 ; p=0.88\right)$. Cannabis users and healthy controls did not differ in regard to PPI $(\mathrm{F}(1.31)=0.13$; $p=0.72) . t$-Tests for independent samples between MDMA

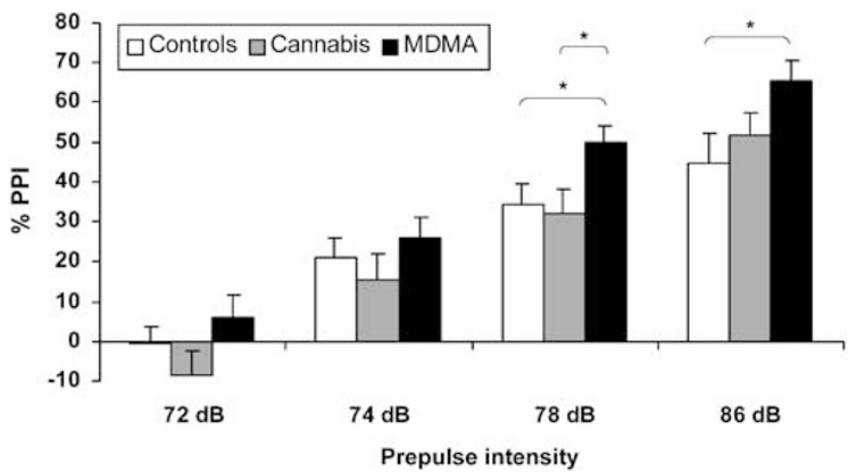

Figure I Percent PPI of prepulse trials (means \pm SEM). ${ }^{*} p<0.05$.

users and healthy controls revealed a significant effect in the two most intensive PP conditions $\left(t_{78 \mathrm{~dB}}(32)=2.30 ; p<0.05\right.$ (two tailed); $t_{86 \mathrm{~dB}}(32)=2.22 ; p<0.05$ (two tailed)). $t$-Tests for independent samples between MDMA users and cannabis users revealed a significant effect in the $78-\mathrm{dB}$ PP condition $\left(t_{78 \mathrm{~dB}}(31)=2.47 ; p<0.05\right.$ (two tailed)) and strong trends in the $72-$ and $86-\mathrm{dB}$ PP conditions $\left(t_{72 \mathrm{~dB}}(31)=1.75 ; p=0.09 ; t_{86 \mathrm{~dB}}(31)=1.73 ; p<0.09\right.$ (two 
tailed)]. $t$-Tests for independent samples of all PP conditions between cannabis users and healthy controls revealed no significant differences.

\section{Habituation}

Figure 2 shows the habituation curve of ASR diagrammed as one initial 116-dB-pulse-alone (PA) trial and following six blocks, where each block contains two 116- $\mathrm{dB}$ PA. The process of habituation was not different among groups. An ANOVA (block $\times$ group, with repeated measures at factor block and smoking as a covariable) revealed a significant main effect of the factor block, reflecting within-session habituation $(\mathrm{F}(5.235)=18.53 ; p<0.001)$, but no other main effects. ANOVA between the MDMA and the control groups, respectively (PP intensity $\times$ group, with repeated measures at PP factor intensity), are shown, also with no other main effects.

\section{Startle Reactivity}

Figure 3 shows the general startle reactivity measured in three variables: the initial PA trial, the first block of PA, and the overall mean of all PAs. ANOVA performed for the groups showed no significant differences in these variables. However, there was a weak trend: the initial PA trial produced less startle reaction in the cannabis group than did the MDMA group $(t(31)=-1.5 ; p=0.15$ (two tailed)) and the healthy controls $(t(31)=-1.5 ; p=0.15$ (two tailed)). This trend disappeared in more reliable measures of startle reactivity, such as the first block of PA or the overall mean of all PAs.

\section{Correlation of ASR Measurement With Demographic Data And Drug Consumption}

The percent PPI of all conditions, variables of startle reactivity, and percent habituation between blocks 1 and 6 correlate neither with period of abstinence (days) of MDMA or cannabis (data are shown in Table 3) nor with age, length of education, or verbal IQ. Furthermore, percent PPI, startle reactivity, and habituation did not correlate with cumulative MDMA or cannabis consumption, nor did they correlate with smoking (cigarettes smoked per week).

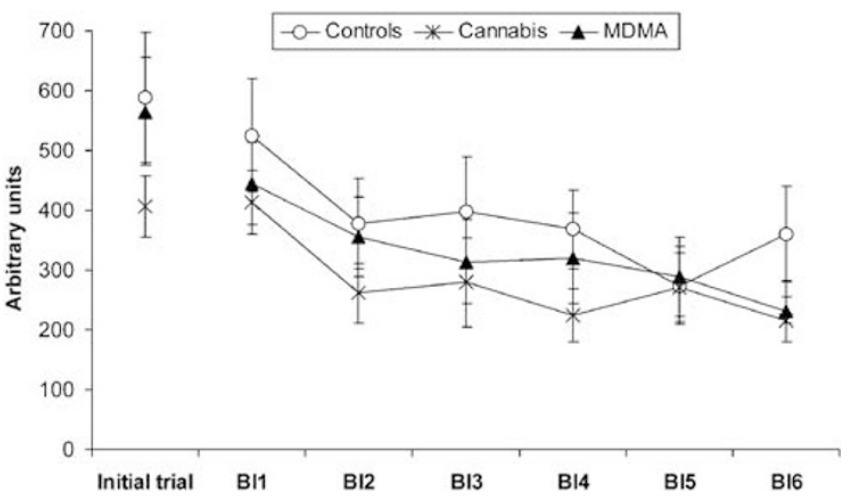

Figure 2 Habituation curve diagrammed as mean amplitude of | 16-dBpulse-alone trials in six blocks and a single initial I |6-dB-pulse-alone trial (means \pm SEM).

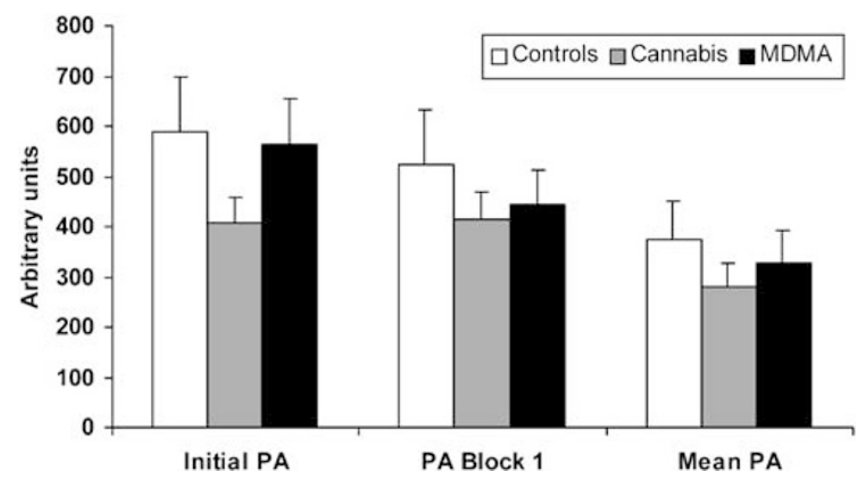

Figure 3 Startle reactivity displayed in the initial I I6-dB PA trial, the first block of I |6-dB PA trials, and the mean amplitude of I | 6-dB-pulse-alone trials (means \pm SEM)

Table 3 Correlations of Percent PPI of all Conditions, Variables of Startle Reactivity, and Percent Habituation Between Blocks I and 6 with Period of Abstinence (days) of MDMA or Cannabis Intake. None of the Correlation Coefficients was Statistically Significant (Pearson's Product Moment Correlation)

\begin{tabular}{lcc}
\hline & $\begin{array}{c}\text { Duration of } \\
\text { abstinence } \\
\text { of } \mathbf{M D M A} \\
\text { (days) } \mathbf{n}=\mathbf{I 9}^{\mathbf{a}}\end{array}$ & $\begin{array}{c}\text { Duration of } \\
\text { abstinence } \\
\text { of cannabis } \\
\text { (days) } \mathbf{n}=\mathbf{3 ~ I}^{\mathbf{a}}\end{array}$ \\
\hline \% PPI 72 dB prepulse & -0.16 & -0.21 \\
\% PPI 74 dB prepulse & 0.02 & 0.35 \\
\% PPI 78 dB prepulse & 0.11 & 0.27 \\
\% PPI 86 dB prepulse & 0.09 & 0.08 \\
Initial pulse-alone trial & 0.02 & -0.11 \\
Pulse-alone trials, block I & 0.15 & -0.16 \\
Pulse-alone trials, mean & -0.07 & -0.21 \\
\% Habituation, block I-6 & 0.27 & -0.06 \\
\hline
\end{tabular}

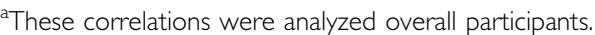

\section{CONCLUSION}

To the best of our knowledge, this is the first controlled study investigating ASR of chronic users of MDMA as well as of chronic users of cannabis compared to that of healthy controls. The object of this experiment was to investigate the functional status of the serotonergic system of chronic but recently abstinent users of MDMA by using measurement of PPI of ASR as a functional marker of the central 5-HT system. Analysis revealed an increase of PPI of ASR in users of MDMA. In addition, no influence of cannabis use on several conditions of ASR was observed.

Previous animal data have shown that application of MDMA causes a selective and sustained reduction of 5-HT levels in the brain (Stone et al, 1986; Commins et al, 1987; Schmidt, 1987; Battaglia et al, 1988; Insel et al, 1989; Wilson et al, 1989; Ali et al, 1993; Scheffel et al, 1998; Hatzidimitriou et al, 1999; Taffe et al, 2001), and there is also some evidence for selectively lowered serotonergic neurotransmission in chronic MDMA users (McCann et al, 1994, 1999). Acute 5-HT depletion decreased PPI in animals and humans consistently (Phillips et al, 2000; Fletcher et al, 
2001; Prinssen et al, 2002), but surprisingly, we found increased PPI for chronic users of MDMA, indicating alterations of neurotransmission other than just lowered 5 -HT. One possible explanation is specific alterations at the receptor level that occur due to chronic MDMA exposure. For example, acute injury with other selective 5-HT neurotoxins can cause denervation supersensitivity of 5-HT receptors (Quattrone et al, 1981; Lucki et al, 1989; Berendsen et al, 1991). An enhancement of PPI due to serotonergic challenge is relatively uncommon (for a review, see Braff et al, 2001; Geyer et al, 2001). For rodents, acute application of the partial 5- $\mathrm{HT}_{1 \mathrm{~A}}$ agonist buspirone (Johansson et al, 1995), as well as the $5-\mathrm{HT}_{2 \mathrm{~A}}$ antagonist M100907 (Zhang et al, 1997), increased PPI. For humans, the mixed $5-\mathrm{HT}_{2}$ and $5-\mathrm{HT}_{1}$ agonist psilocybin also increased PPI (Gouzoulis-Mayfrank et al, 1998). Thus, our results of increased PPI in chronic but recently abstinent MDMA users may have been due to alterations of the sensitivity and/or the density of $5-\mathrm{HT}_{2}$ and/or $5-\mathrm{HT}_{1}$ receptors due to long-term MDMA exposure. This hypothesis is consistent with the findings of a number of studies that have tracked long-term changes in specific 5-HT receptors: McGregor et al (2003) reported dose-dependent alterations of cerebral $5-\mathrm{HT}_{1 \mathrm{~B}}$ and $5-\mathrm{HT}_{2 \mathrm{~A} / 2 \mathrm{C}}$ receptor densities after MDMA exposure in rats. McCreary et al (1999) showed supersensitivity of $5-\mathrm{HT}_{1 \mathrm{~B}}$ and/or $5-\mathrm{HT}_{1 \mathrm{~A}}$ receptors after withdrawal from repeated MDMA treatment in rats. Two studies showed an increase of $5-\mathrm{HT}_{1 \mathrm{~A}}$ receptor density in the frontal cortex of rats after single and repeated MDMA treatment (Aguirre et al, 1995, 1998). Furthermore, it has also been reported that high-dose MDMA treatment causes transient upregulation of $5-\mathrm{HT}_{1 \mathrm{~B}}$ receptors (Sexton et al, 1999). A higher $5-\mathrm{HT}_{2 \mathrm{~A}}$ receptor density in cortical regions has been shown in former MDMA users and in rats 30 days after MDMA treatment, whereas current MDMA users and rats treated with MDMA $6 \mathrm{~h}$ prior have shown lower $5-\mathrm{HT}_{2 \mathrm{~A}}$ receptor density in cortical regions (Reneman et al, 2002). With our method, we could not differentiate between altered 5-HT receptor sensitivity and density, and future studies should try to deconstruct these different mechanisms.

An alternative explanation for the increased PPI in users of MDMA would be acute effects of the drug, as previously reported (Vollenweider et al, 1999; Liechti et al, 2001). In fact, the duration of abstinence was at least 3 days, and transient mood disturbances within 1 week following MDMA intake have been previously reported (Parrott and Lasky, 1998). However, the mean period of MDMA abstinence was 15.29 (SEM, 2.64) days, the median was 14 days, and more than $75 \%$ of our MDMA users reported an abstinence of MDMA for more than 1 week. Furthermore, the period of abstinence of MDMA did not correlate with PPI. These facts suggest that the increase of PPI probably cannot be explained by an acute pharmacological effect of MDMA. In the MDMA and the cannabis groups, the duration of abstinence from cannabis was considerably shorter, and it is known that there is a withdrawal syndrome lasting for several days following cessation of cannabis use (Haney et al, 1999). However, the fact that the duration of abstinence from cannabis in both groups was comparable but that an increase of PPI was shown only in the MDMA group suggests that the observed increase of PPI is not an acute effect of cannabis cessation. This assumption is further supported by the lack of a correlation between the duration of abstinence of cannabis and PPI.

One limitation of this study is that the history of drug consumption was assessed only by using subjective reports. Thus, the reliability of the data must be questioned. A drug usage screening would be helpful to at least control for acute and postacute drug effects within a few days before assessment. A related problem concerns the fact that the exact consumption pattern of drugs across an individual's lifetime is objectively not calculable (Curran, 2000). However, Stuerenburg et al (2002) found a concordance of $91.3 \%$ between the self-reported drug intake and toxicological analyses of hair specimens in a sample of German MDMA users.

The habituation as well as the startle reactivity of ASR of MDMA users was not altered. This finding is consistent with the only study of ASR after chronic administration of MDMA in rats (Slikker et al, 1989). Although the MDMA group showed a slower but more sustainable habituation, the overall process of habitation was not different among the groups. Furthermore, the MDMA users investigated in this study showed other functional consequences, such as severe impairments of verbal declarative memory and decision making, and they exhibited glucose hypometabolism as measured by 18-FDG positron emission tomography in the frontal cortex, brainstem, and thalamus (data not shown). These data will be published elsewhere.

We investigated a clinical control group of cannabis users to account for a possible effect of the existing concomitant use of cannabinoids on the ASR of our MDMA users and to estimate the influences of personality variables in illegal drug users. Since the increase of PPI was measured between MDMA users and healthy controls as well as between MDMA users and cannabis users, our results could not be explained by personality factors or concomitant cannabis abuse by MDMA users.

Cannabis users did not show any significant alterations of startle reactivity, PPI, or habituation of ASR. This is remarkable insofar as it has been previously shown that acute application of a cannabinoid receptor agonist $\left(\mathrm{CB}_{1}\right)$ decreases PPI (Schneider and Koch, 2002) and/or startle reactivity (Mansbach et al, 1996; Martin et al, 2003) in rats. However, contradictory results have been reported by Stanley-Cary et al (2002), who observed that equivalent doses of the $\mathrm{CB}_{1}$ receptor agonist CP 55,940 increase startle amplitude and PPI in rats. Perhaps these are only acute effects of cannabinoid receptor agonist on ASR; the subjects of the cannabis group were drug free for at least 3 days, and the mean duration of abstinence from cannabis was 6.6 (SEM, 4.9) days. In fact, tetrahydrocannabinol (THC) plasma elimination half-lives ranged between 18 and $50 \mathrm{~h}$ after radiolabeled THC administration (Huestis and Cone, 1998). An elimination of $95 \%$ of a substance takes about five half-lives; therefore, THC takes 3.8-10.4 days to be almost fully eliminated. Even so, we found no significant differences in ASR between the cannabis group and our healthy controls. To the best of our knowledge, there are to date no published data on the influence of cannabis, its psychoactive components, or cannabinoid receptor agonists on PPI and habituation of ASR in humans. 
A fundamental problem of investigations in this research area is to differentiate between the acute and chronic effects of drugs on ASR. Most of the studies of rodents and humans reported above have been carried out by using acute administration of psychotropic drugs. Little is known about the chronic effects on ASR and underlying mechanisms of neurotransmission. There are different and interesting effects of chronic $v s$ acute drug effects, and studies with acute or chronic drug application are difficult to compare because of minimal or no data regarding chronic effects. In the future, it will be necessary to study long-term effects of drugs on ASR combined with neurochemical investigations to enhance our knowledge of psychotropic drug effects on ASR. In order to use this paradigm in animal models for psychiatric disorders, it would be of particular interest to determine whether the effect reported here may be replicated in rodents.

Given our results, one could speculate that the empirical findings supported functional consequences of MDMA consumption, such as memory disturbance, elevated impulsivity, or increased risk for psychiatric illness, are less an effect of the supposed 5-HT depletion than they are of changes at the receptor level. Further studies will be needed in order to confirm this speculation with a more specific methodological inventory, which should include combined measurements of behavioral and neurochemical variables. Perhaps this will provide new possibilities for the prevention or treatment of neurotoxic lesions due to MDMA misuse.

\section{REFERENCES}

Aguirre N, Ballaz S, Lasheras B, Delrio J (1998). MDMA (Ecstasy) enhances $5-\mathrm{HT}_{1 \mathrm{~A}}$ receptor density and 8-OH-DPAT-induced hypothermia-blockade by drugs preventing 5-hydroxytryptamine depletion. Eur J Pharmacol 346: 181-188.

Aguirre N, Galbete JL, Lasheras B, Delrio J (1995). Methylenedioxymethamphetamine induces opposite changes in central preand postsynaptic 5- $\mathrm{HT}_{1 \mathrm{~A}}$ receptors in rats. Eur J Pharmacol 281 : 101-105.

Ali SF, Newport GD, Scallet AC, Binienda Z, Ferguson SA, Bailey JR et al (1993). Oral administration of 3,4-methylenedioxymethamphetamine (MDMA) produces selective serotonergic depletion in the nonhuman primate. Neurotoxicol Teratol 15: 91-96.

Battaglia G, Yeh SY, DeSouza EB (1988). MDMA-induced neurotoxicity: parameters of degeneration and recovery of brain serotonin neurones. Pharmacol Biochem Behav 29: 267-274.

Berendsen HH, Broekkamp CL, van Delft AM (1991). Depletion of brain serotonin differently affects behaviors induced by $5 \mathrm{HT} 1 \mathrm{~A}$, 5HT1C, and 5HT2 receptor activation in rats. Behav Neural Biol 55: 214-226.

Braff DL, Geyer MA, Swerdlow NR (2001). Human studies of prepulse inhibition of startle: normal subjects, patient groups, and pharmacological studies. Psychopharmacology 156: 234-258.

Braff DL, Grillon C, Geyer MA (1992). Gating and habituation of the startle reflex in schizophrenic patients. Arch Gen Psychiatry 49: 206-215.

Carlton PL, Advokat C (1973). Attenuated habituation due to parachlorophenylalanine. Pharmacol Biochem Behav 1: 657-663.

Castellanos FX, Fine EJ, Kaysen D, Marsh WL, Rapoport JL, Hallett M (1996). Sensorimotor gating in boys with Tourette's syndrome and ADHD: preliminary results. Biol Psychiatry 39: 33-41.
Christophersen AS (2000). Amphetamine designer drugs - an overview and epidemiology. Toxicol Lett 112-113: 127-131.

Commins DL, Vosmer G, Virus RM, Woolverton WL, Schuster CR, Seiden LS (1987). Biochemical and histological evidence that methylenedioxymethamphetamine (MDMA) is toxic to neurons in the rat brain. J Pharmacol Exp Ther 241: 338-345.

Conner RL, Stolk JM, Barchas JD, Levine S (1970). Parachlorophenylalanine and habituation to repetitive auditory startle stimuli in rats. Physiol Behav 5: 1215-1219.

Croft RJ, Mackay AJ, Mills AT, Gruzelier JG (2001). The relative contributions of ecstasy and cannabis to cognitive impairment. Psychopharmacology 153: 373-379.

Curran HV (2000). Is MDMA ('Ecstasy') neurotoxic in humans? An overview of evidence and of methodological problems in research. Neuropsychobiology 42: 34-41.

Daumann J, Pelz S, Becker S, Tuchtenhagen F, GouzoulisMayfrank F (2001). Psychological profile of abstinent recreational Ecstasy (MDMA) users and significance of concomitant cannabis use. Hum Psychopharmacol Clin Exp 16: 627-633.

Davis M, Sheard MH (1976). p-Chloroamphetamine (PCA): acute and chronic effects on habituation and sensitization of the acoustic startle response in rats. Eur J Pharmacol 35: 261-273.

Davis MT, Parisi DS, Gendelman M, Tischler JH (1982). Habituation and sensitization of startle reflexes elicited electrically from the brainstem. Science 218: 688-690.

Fletcher PJ, Selhi ZF, Azampanah A, Sills TL (2001). Reduced brain serotonin activity disrupts prepulse inhibition of the acoustic startle reflex. Effects of 5,7-dihydroxytryptamine and p-chlorophenylalanine. Neuropsychopharmacology 24: 399-409.

Geyer MA, Braff DL (1987). Startle habituation and sensorimotor gating in schizophrenia and related animal models. Schizophr Bull 13: 643-668.

Geyer MA, Krebs-Thomson K, Braff DL, Swerdlow NR (2001). Pharmacological studies of prepulse inhibition models of sensorimotor gating deficits in schizophrenia: a decade in review. Psychopharmacology 156: 117-154.

Geyer MA, Tapson GS (1988). Habituation of tactile startle is altered by drugs acting on serotonin- 2 receptors. Neuropsychopharmacology 1: 135-147.

Gouzoulis-Mayfrank E, Becker S, Pelz S, Tuchtenhagen F, Daumann J (2002a). Neuroendocrine abnormalities in recreational ecstasy (MDMA) users: is it ecstasy or cannabis? Biol Psychiatry 51: 766-769.

Gouzoulis-Mayfrank E, Daumann J, Sass H (2002b). Chronic neurotoxic damage in ecstasy (MDMA) users. Review of the current state of research. Nervenarzt 73: 405-421.

Gouzoulis-Mayfrank E, Heekeren K, Thelen B, Lindenblatt $\mathrm{H}$, Kovar KA, Sass H et al (1998). Effects of the hallucinogen psilocybin on habituation and prepulse inhibition of the startle reflex in humans. Behav Pharmacol 9: 561-566.

Graham FK (1975). The more or less startling effects of weak prestimulation. Psychophysiology 12: 238-248.

Groves PM, Thompson RF (1970). Habituation: a dual-process theory. Psychol Rev 77: 419-450.

Haney M, Ward AS, Comer SD, Foltin RW, Fischman MW (1999). Abstinence symptoms following smoked marijuana in humans. Psychopharmacology 141: 395-404.

Hatzidimitriou G, McCann DU, Ricaurte GA (1999). Altered serotonin innervation patterns in the forebrain of monkeys treated with $(+/-) 3,4$-methylenedioxymethamphetamine seven years previously: factors influencing abnormal recovery. J Neurosci 19: 5096-5107.

Hoffman HS, Ison JR (1980). Reflex modification in the domain of startle: I. Some empirical findings and their implications for how the nervous system processes sensory input. Psychol Rev 87: 175-189.

Hoffman HS, Searle JL (1968). Acoustic and temporal factors in the evocation of startle. J Acoust Soc Am 43: 269-282. 
Huestis MA, Cone EJ (1998). Urinary excretion half-life of 11-nor9-carboxy-delta9-tetrahydrocannabinol in humans. Ther Drug Monit 20: 570-576.

Insel TR, Battaglia G, Johannessen JN, Marra S, De Souza EB (1989). 3,4-Methylene-dioxymethamphetamine ('ecstasy') selectively destroys brain serotonin terminals in rhesus monkeys. J Pharmacol Exp Ther 249: 713-720.

Johansson C, Jackson DM, Zhang J, Svensson L (1995). Prepulse inhibition of acoustic startle, a measure of sensorimotor gating: effects of antipsychotics and other agents in rats. Pharmacol Biochem Behav 52: 649-654.

Kehne JH, Padich RA, McCloskey TC, Taylor VL, Schmidt CJ (1996). 5-HT modulation of auditory and visual sensorimotor gating: I. Effects of 5-HT releasers on sound and light prepulse inhibition in Wistar rats. Psychopharmacology 124: 95-106.

Kish SJ (2002). How strong is the evidence that brain serotonin neurons are damaged in human users of ecstasy? Pharmacol Biochem Behav 71: 845-855.

Koch M (1999). The neurobiology of startle. Prog Neurobiol 59: 107-128.

Lehrl S (1999). Mehrfachwahl-Wortschatz-Intelligenztest (MWT-B), 4th ed Hogrefe: Göttingen.

Liechti ME, Geyer MA, Hell D, Vollenweider FX (2001). Effects of MDMA (Ecstasy) on prepulse inhibition and habituation of startle in humans after pretreatment with Citalopram, Haloperidol, or Ketanserin. Neuropsychopharmacology 24: 240-252.

Lucki I, Ward HR, Frazer A (1989). Effect of 1-( $m$-chlorophenyl)piperazine and 1-( $m$-trifluoromethylphenyl)piperazine on locomotor activity. J Pharmacol Exp Ther 249: 155-164.

Mansbach RS, Braff DL, Geyer MA (1989). Prepulse inhibition of the acoustic startle response is disrupted by $N$-ethyl-3,4methylenedioxyamphetamine (MDEA) in the rat. Eur J Pharmacol 167: 49-55.

Mansbach RS, Rovetti CC, Winston EN, Lowe III JA (1996). Effects of the cannabinoid CB1 receptor antagonist SR141716A on the behavior of pigeons and rats. Psychopharmacology (Berl) 124: $315-322$.

Martin RS, Secchi RL, Sung E, Lemaire M, Bonhaus DW, Hedley LR et al (2003). Effects of cannabinoid receptor ligands on psychosis-relevant behavior models in the rat. Psychopharmacology (Berl) 165: 128-135.

Martinez DL, Geyer MA (1997). Characterization of the disruptions of prepulse inhibition and habituation of startle induced by alpha-ethyltryptamine. Neuropsychopharmacology 16: 246-255.

McCann UD, Eligulashvili V, Ricaurte GA (2000). 3,4-Methylenedioxymethamphetamine ('Ecstasy')-induced serotonin neurotoxicity: clinical studies. Neuropsychobiology 42: 11-16.

McCann UD, Mertl M, Eligulashvili V, Ricaurte GA (1999). Cognitive performance in (+/-) 3,4-methylenedioxymethamphetamine (MDMA, 'ecstasy') users: a controlled study. Psychopharmacology 143: 417-425.

McCann UD, Ridenour A, Shaham Y, Ricaurte GA (1994). Serotonin neurotoxicity after (+/-) 3,4-methylenedioxymethamphetamine (MDMA; 'Ecstasy'): a controlled study in humans. Neuropsychopharmacology 10: 129-138.

McCreary AC, Bankson MG, Cunningham KA (1999). Pharmacological studies of the acute and chronic effects of (+)-3, 4methylenedioxymethamphetamine on locomotor activity: role of 5-hydroxytryptamine(1A) and 5-hydroxytryptamine(1B/1D) receptors. J Pharmacol Exp Ther 290: 965-973.

McGregor IS, Clemens KJ, Van Der Plasse G, Li KM, Hunt GE, Chen $\mathrm{F}$ et al (2003). Increased anxiety 3 months after brief exposure to MDMA ('Ecstasy') in rats: association with altered 5HT transporter and receptor density. Neuropsychopharmacology 28: $1472-1484$.

Montoya AG, Sorrentino R, Lukas SE, Price BH (2002). Long-term neuropsychiatric consequences of 'ecstasy' (MDMA): a review. Harv Rev Psychiatry 10: 212-220.
Morgan MJ (2000). Ecstasy (MDMA): a review of its possible persistent psychological effects. Psychopharmacology 152: 230-248.

Overstreet DH (1977). Pharmacological approaches to habituation of the acoustic startle response in rats. Physiol Psychol 5: 230-238.

Parrott AC (2000). Human research on MDMA (3,4-methylenedioxymethamphetamine) neurotoxicity: cognitive and behavioural indices of change. Neuropsychobiology 42: 17-24.

Parrott AC (2001). Human psychopharmacology of Ecstasy (MDMA): a review of 15 years of empirical research. Hum Psychopharmacol Clin Exp 16: 557-577.

Parrott AC, Lasky J (1998). Ecstasy (MDMA) effects upon mood and cognition: before, during and after a Saturday night dance. Psychopharmacology 139: 261-268.

Phillips MA, Oxtoby EK, Langley RW, Bradshaw CM, Szabadi E (2000). Effects of acute tryptophan depletion on prepulse inhibition of the acoustic startle (eyeblink) response and the N1/P2 auditory evoked response in man. J Psychopharmacol 14: 258-265.

Prinssen EP, Assie MB, Koek W, Kleven MS (2002). Depletion of 5HT disrupts prepulse inhibition in rats: dependence on the magnitude of depletion, and reversal by a 5-HT precursor. Neuropsychopharmacology 26: 340-347.

Quattrone A, Schettini G, Annunziato L, Di Renzo G (1981). Pharmacological evidence of supersensitivity of central serotonergic receptors involved in the control of prolactin secretion. Eur J Pharmacol 76: 9-13.

Reneman L, Endert L, de Bruin K, Lavalaye J, Feenstra MG, de Wolff FA et al (2002). The acute and chronic effects of MDMA ('ecstasy') on cortical 5-HT2A receptors in rat and human brain. Neuropsychopharmacology 26: 387-396.

Rudnick G, Wall SC (1992). The molecular mechanism of 'ecstasy' (3,4-methylenedioxymethamphetamin, MDMA): serotonin transporters are targets for MDMA-induced serotonin release. Proc Natl Acad Sci USA 89: 1817-1821.

Scheffel U, Szabo Z, Mathews WB, Finley PA, Dannals RF, Ravert $\mathrm{HT}$ et al (1998). In vivo detection of short- and long-term MDMA neurotoxicity - a positron emission tomography study in the living baboon brain. Synapse 29: 183-192.

Schmidt CJ (1987). Neurotoxicity of the psychedelic amphetamine, methylenedioxymethamphetamine. J Pharmacol Exp Ther 240: $1-7$.

Schneider M, Koch M (2002). The cannabinoid agonist WIN 55,212-2 reduces sensorimotor gating and recognition memory in rats. Behav Pharmacol 13: 29-37.

Sexton TJ, McEvoy C, Neumaier JF (1999). 3,4-Methylenedioxymethampetamine ('Ecstasy') transiently increases striatal 5$\mathrm{HT}_{1 \mathrm{~B}}$ binding sites without altering $5-\mathrm{HT}_{1 \mathrm{~B}} \mathrm{mRNA}$ in rat brain. Mol Psychiatry 4: 63-69.

Slikker Jr W, Holson RR, Ali SF, Kolta MG, Paule MG, Scallet AC et al (1989). Behavioral and neurochemical effects of orally administered MDMA in the rodent and nonhuman primate. Neurotoxicology 10: 529-542.

Stanley-Cary CC, Harris C, Martin-Iverson MT (2002). Differing effects of the cannabinoid agonist, CP 55,940, in an alcohol or Tween 80 solvent, on prepulse inhibition of the acoustic startle reflex in the rat. Behav Pharmacol 13: 15-28.

Stone DM, Stahl DC, Hanson GR, Gibb JW (1986). The effects of 3,4-methylenedioxymethamphetamine (MDMA) and 3,4-methylenedioxyamphetamine (MDA) on monoaminergic systems in the rat brain. Eur J Pharmacol 128: 41-48.

Stuerenburg HJ, Petersen K, Baumer T, Rosenkranz M, Buhmann C, Thomasius R (2002). Plasma concentrations of 5-HT, 5-HIAA, norepinephrine, epinephrine, and dopamine in ecstasy users. Neuroendocrinol Lett 23: 259-261.

Swerdlow NR, Benbow CH, Zisook S, Geyer MA, Braff DL (1993). A preliminary assessment of sensorimotor gating in patients with obsessive compulsive disorder. Biol Psychiatry 33: 298-301. 
Swerdlow NR, Braff DL, Geyer MA (1999). Cross-species studies of sensorimotor gating of the startle reflex. Ann N Y Acad Sci 877: 202-216.

Swerdlow NR, Karban B, Ploum Y, Sharp R, Geyer MA, Eastvold A (2001). Tactile prepuff inhibition of startle in children with Tourette's syndrome: in search of a 'fMRI-friendly' startle paradigm. Biol Psychiatry 50: 578-585.

Taffe MA, Weed MR, Davis S, Huitron-Resendiz S, Schroeder R, Parsons LH et al (2001). Functional consequences of repeated (+/-) 3,4-methylenedioxymethamphetamine (MDMA) treatment in rhesus monkeys. Neuropsychopharmacology 24: 230-239.
Vollenweider FX, Remensberger S, Hell D, Geyer MA (1999). Opposite effects of 3,4-methylenedioxymethamphetamine (MDMA) on sensorimotor gating in rats versus healthy humans. Psychopharmacology 143: 365-372.

Wilson MA, Ricaurte GA, Molliver ME (1989). Distinct morphological classes of serotonergic axons in primates exhibit differential vulnerability to the psychotropic drug 3,4-methylenedioxymethamphetamine. Neuroscience 28: 121-137.

Zhang J, Engel JA, Jackson DM, Johansson C, Svensson L (1997). (-)Alprenolol potentiates the disrupting effects of dizocilpine on sensorimotor function in the rat. Psychopharmacology 132: 281-288. 